\title{
Role of Biologics and Other Therapies in Stricturing Crohn's Disease: What Have We Learnt So Far?
}

\author{
D. Sorrentino
}

Chair of Gastroenterology, Department of Clinical and Experimental Pathology, University of Udine School of Medicine, Udine, Italy

\section{Key Words}

Crohn's disease - Inflammatory and fibrotic strictures • Infliximab

\begin{abstract}
Background: Therapy of strictures, one of the most common complications of Crohn's disease (CD), remains a challenging task in gastroenterology. While infliximab is widely recognized as being very effective in active $C D$, it has been reported to cause strictures in some patients. As a consequence, essentially by inference, many clinicians have chosen not to use it in the presence of strictures. Aims: To find evidence in the available data that infliximab does not cause strictures and that there is no rational basis to avoid its a priori use when a stricture is already present. In addition, to review what is currently known on the general management of strictures in CD. Methods: Discussion of the data that led to the hypothesis of a causal association between infliximab and strictures. Review of the mechanisms and the risk factors for stricture development in CD; of the different types of CDrelated strictures; of the available means to distinguish them, and of the literature related to the efficacy and safety of infliximab as well as other biologics and other therapies in different stricturing scenarios. Results and Conclusions: Although larger controlled studies are due in the near future, current evidence indicates that infliximab does not cause
\end{abstract}

\section{KARGER}

Fax +41613061234

E-Mail karger@karger.ch

www.karger.com
(C) 2008 S. Karger AG, Basel

0012-2823/08/0771-0038\$24.50/0

Accessible online at:

www.karger.com/dig strictures in CD. The drug appears safe and effective in the presence of an inflammatory stenosis while being predictably ineffective, but not harmful, in the presence of fibrosis. Different stricturing scenarios in CD must be clearly distinguished for proper management of this complication.

Copyright $\odot 2008$ S. Karger AG, Basel

\section{Introduction}

Strictures, both in the small intestine and colon, represent one of the most common complications of Crohn's disease (CD) and the main cause of hospitalization and costs in the management of patients affected by this pathology [1]. Therapy remains a challenging and yet fundamental task for the practicing gastroenterologist today. What follows is a review focusing on the role of biologics, essentially infliximab, in stricturing intestinal CD. The known mechanisms of stricture formation, risk factors for stricture development, differential diagnosis of various types of strictures in CD as well as therapies other than infliximab will also be discussed. Since the data related to therapeutic strategies in stricturing CD are still preliminary, the conclusions related to this issue reflect in part the author's experience and opinion as well as the available evidence. Larger controlled studies are due in the near future.
Prof. Dario Sorrentino

Cattedra di Gastroenterologia, Azienda Ospedaliero-Universitaria Padiglione Scrosoppi, Via Colugna

IT-33100 Udine (Italy)

Tel. +39 0432559 803, Fax +39 0432559 548, E-Mail sorrentino@uniud.it 


\section{Background}

Since 1995 infliximab, an anti-TNF- $\alpha$ monoclonal antibody, has been widely recognized as one of the most effective medications in active CD [2]. With this therapy, clinical improvement is accompanied by significant healing of the endoscopic lesions and the disappearance of the mucosal inflammatory infiltrate through a downregulation of inflammatory mediators $[3,4]$. Yet, it has been reported that strictures may develop in some patients [57] after infliximab treatment, possibly because rapid mucosal healing may induce fibrosis in the submucosa and in the deeper layers of the gut wall. Although the authors of these initial observations never directly implied it, many clinicians have chosen, essentially by inference and/or personal experience, not to use infliximab in the presence of strictures. Indeed, the manufacturer's recommendations have long discouraged its use in the presence of intestinal stenoses [8]. Paradoxically, according to the step-up protocol [9], the drug has generally been used as a last resource in $\mathrm{CD}$, precisely the situation in which stenoses are exceedingly common. As a consequence, a large number of $\mathrm{CD}$ patients who may have benefited from infliximab therapy may not have been treated at all.

\section{Does Infliximab Cause Strictures? The Data and the Literature Revisited}

Published data apparently showing a cause-effect relationship between infliximab and stricture development in CD involved a limited number of observations. In particular, D'Haens et al. [5] show a new stenosis occurring after treatment in 1 of 30 patients. Likewise, only small series of patients developing this apparent complication have been described in preliminary form by Vasilopoulos et al. [6] and by Toy et al. [7]. Although the observations described by these investigators remain solid and reproducible, none of these reports detailed the clinical cases (i.e. severity and duration of the disease and other risk factors for stricture development). Furthermore, although theoretical evidence exists suggesting that TNF- $\alpha$ may interfere with fibrosis in some tissues [10] (see below), other evidence indicates that its inhibitor infliximab may actually be antifibrogenic in CD [11].

That infliximab treatment may not be directly linked to stricture development is also supported by a recent report by Lichtenstein et al. [12]. On the basis of a detailed analysis of the ongoing observational TREAT registry and the ACCENT I study, these authors have shown that $\mathrm{CD}$ severity and duration, ileal disease and new corticosteroid use, but not infliximab therapy, are associated with a greater risk of developing strictures when data are analyzed by multivariable analyses. Only when the data of the TREAT registry were subjected to univariate analyses did strictures appear to occur at a greater rate in infliximab-treated patients compared with patients who received other treatments. Thus, previous inferential conclusions may indeed reflect the long held strategy to use infliximab in more seriously ill patients such as those in a later stage of disease, with several risk factors and already probably irreversibly bound to develop strictures [9].

\section{The State of the Art}

Does the analysis by Lichtenstein et al. [12] change the way we use infliximab in CD? In clinical practice few clinicians are concerned that this drug will eventually cause strictures in a patient who does not have any [13]. Instead, a fundamental issue raised by this paper is whether, in light of the above results, one could safely treat a patient who already has a stenosis with infliximab.

Three types of strictures have been described in CD [14]: anastomotic (resulting from surgery), inflammatory (due to cell infiltration and edema in the bowel wall), and fibrotic (due to collagen deposition), all of which may result in obstruction.

Anastomotic (post-surgical) strictures are often short and linear and may appear several months after surgery in the complete absence of disease recurrence (fig. 1). Only inflammatory and fibrotic strictures are part of the natural history of the disease and will be the main focus of the following sections.

It is generally believed that, as an earlier expression of disease, inflammatory stenoses are reversible (i.e. can be managed medically) while fibrotic strictures can only be treated by surgery. However, cell infiltration and fibrosis may coexist in the same stricture and be part of the same ongoing pathological process [15].

\section{How Does a Fibrotic Stricture Form?}

The fibrogenesis in CD is incompletely understood and appears to result from a complex interplay among local inflammatory cells, fibroblasts, smooth muscle cells, and cytokines [10, 16, 17].

A major role in the process is played by the cytokine transforming growth factor- $\beta$ (TGF- $\beta$ ) and by the un- 


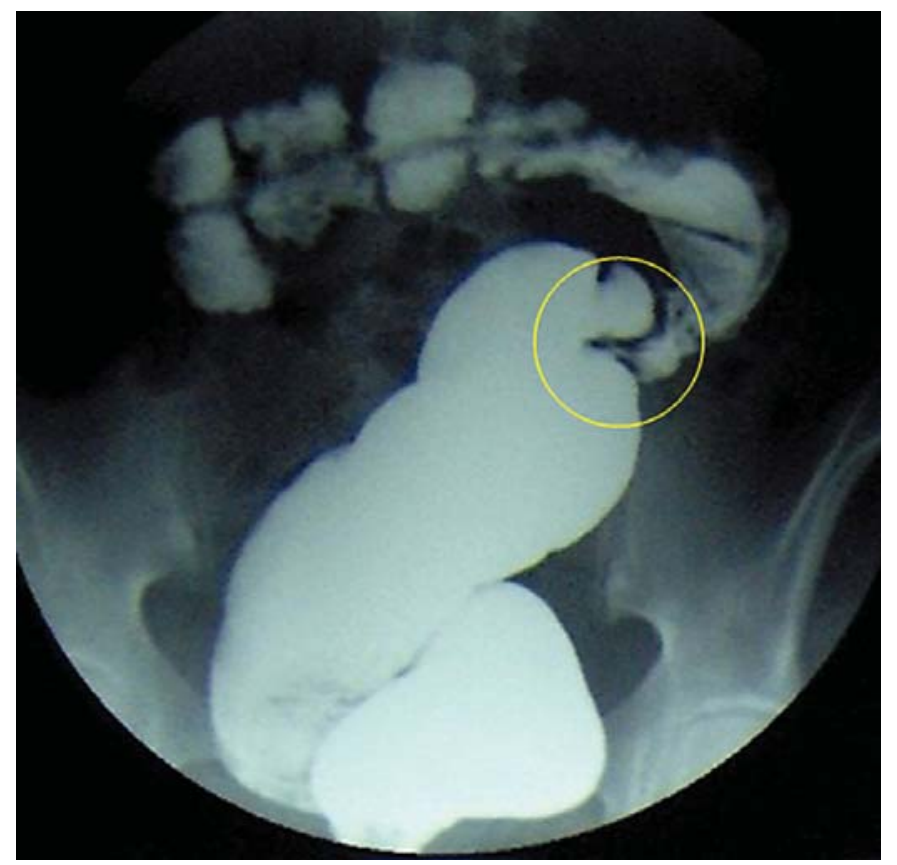

Fig. 1. Postsurgical colonic stricture: barium enema. The patient underwent segmental sigmoid resection 1 year earlier for colonic $\mathrm{CD}$. Note (circle) the short linear narrowing of the lumen in the absence of active disease recurrence.

controlled transformation of resident mesenchymal cells into matrix depositing myofibroblasts [18].

TGF- $\beta$ is a fibrogenic as well as powerful anti-inflammatory cytokine. $\mathrm{CD}$ patients express increased amounts of pro-fibrotic TGF- $\beta 2$ and decreased levels of the inhibitory cytokine TGF- $\beta 3$ [19]. However, this may not be the consequence of a genetic predisposition but may rather reflect local events since this type of cytokine expression is limited to the fibrotic segment of the intestine [19]. Local events are also involved in increased adhesion molecule expression in fibroblasts which is only observed in cells obtained from the serosa of inflamed segments and not in dermal fibroblasts from the edge of the skin incision in CD patients [20]. In turn, greater expression of adhesion molecules and growth factors promotes cell recruitment, cell-cell interaction, and excessive synthesis of the extracellular matrix.

Furthermore, the observed dysregulated matrix metalloproteinase activity, which prevents normal breakdown of deposited matrix with abnormal contractile activity favoring scar contraction and stricture formation, is also confined to fibroblasts isolated from the fibrotic tract of the intestine [16].
TNF- $\alpha$ appears to antagonize TGF- $\beta$-dependent responses by increasing prostacyclin, inducing JNK MAP kinase and Smad 7 expression, each of which has antifibrotic effects [21,22]. However, there is experimental and clinical evidence suggesting that infliximab, which inhibits TNF- $\alpha$, may be antifibrogenic. Indeed, in CD patients, infliximab appears capable of decreasing the serum levels of basic fibroblast growth factor and vascular endothelial growth factor, both known to be involved in the process of fibrosis [23]. In addition, anti-TNF antibodies appear capable of functionally modulating the myofibroblasts of CD patients [11]. Thus, the clinical significance and the therapeutic implications of the above observations in stricturing $\mathrm{CD}$ remain unknown.

In conclusion, cytokine expression patterns suggest that the specific fibrogenic phenotype in CD may not be due to a genetic background but, instead, it may result from the microenvironment in strictured bowel segments [16].

\section{What Are the Risk Factors for the Development of Fibrotic Strictures?}

As discussed above, $\mathrm{CD}$ severity and duration, ileal disease and new corticosteroid use, but not infliximab therapy, appear to be associated with a greater risk of developing strictures $[12,24]$. However we still do not know whether some $\mathrm{CD}$ patients are destined to develop this complication while others may never do [25]. The Montreal classification distinguishes, among the others, an inflammatory and a stricturing form of CD [26] but, in contrast with previous classifications, recognizes that disease behavior is dynamic over time, e.g. that one form may evolve into the other $[27,28]$.

Many studies [29-32] but not all [33] have found that the CARD15 polymorphism is associated with early stricture development. Since current data often show that NOD2/CARD15 mutations in CD are associated with ileal involvement, more studies may be needed to determine whether these mutations are also always associated with a higher risk of stricturing disease [29] or whether instead the risk solely depends on disease location [12]. Unfortunately, as yet, the correlation between CARD15 polymorphisms, which by themselves are only associated with a portion of $\mathrm{CD}$ cases regardless of disease behavior, and clinical and histopathological features has at best limited clinical applicability [34].

By contrast, TNF receptor gene polymorphisms seem to be associated with a reduced risk of stricturing disease [35]. 
Fig. 2. Differential diagnosis between an inflammatory stenosis (A) and a fibrotic stricture (B): small bowel enteroclysis. Note the sharp, fixed and narrow lumen and the presence of a pre-stenotic dilation (arrow) in the fibrotic stricture (B) compared to the wider, less defined margins as well as with the absence of dilation in the inflammatory stenosis (A).
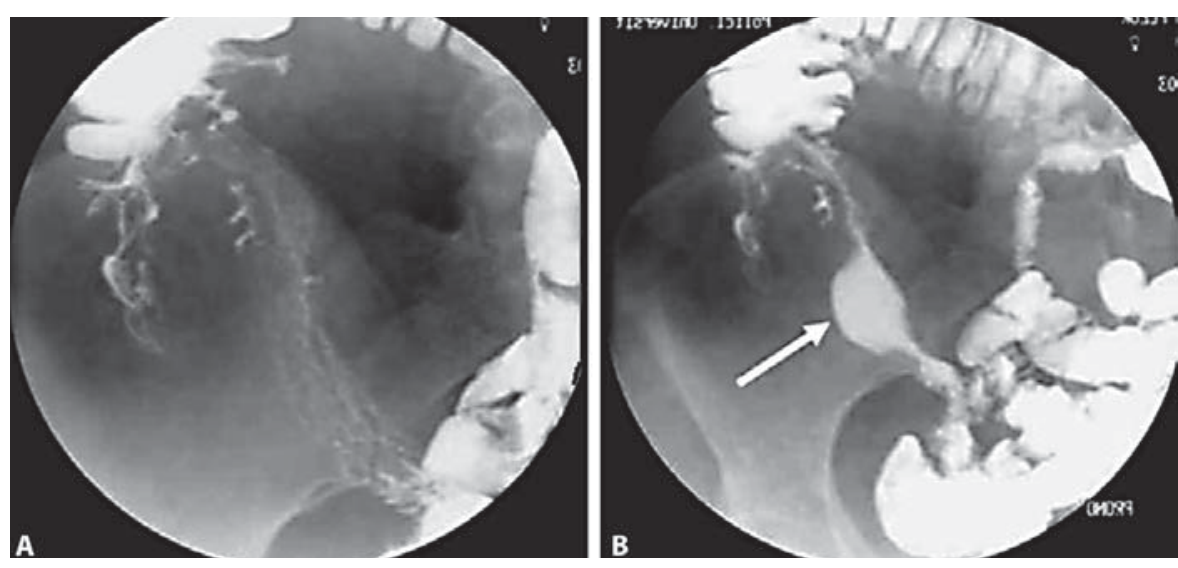

Other studies indicate that an increased level of metalloproteinases in the ileum can be the basis of stricture formation [36]. Still others propose histopathology [37], bowel wall thickness on abdominal ultrasound [38] and anti-ASCA antibodies [39] as possible prognostic factors in stricture formation and bowel obstruction in CD.

In conclusion, there is evidence in favor of a genetic predisposition to develop strictures and there is evidence suggesting that strictures are related to disease duration and the degree of inflammation [10]. The cytokine expression pattern in the affected and normal bowel of $\mathrm{CD}$ patients (see above) suggests that local factors may be more important than genetics. It is possible that the capacity of scar formation, in the intestine as well as in other organs and tissues such as the skin, may depend on host predisposition. However, we cannot at the moment predict with certainty who will and who will not develop fibrotic strictures. Nevertheless, we do know that this complication is extremely frequent.

\section{How Do We Distinguish an Inflammatory from a Fibrotic Stricture?}

The differential diagnosis between a fibrotic and an inflammatory narrowing of the lumen is difficult. Furthermore, the two processes may actually coexist. In such a case the challenge is to quantify the two components and, ideally, to manage the patient accordingly.

While the initial diagnosis of any stricture, regardless of its nature, is often made by endoscopy, the role of this procedure in the differential diagnosis of strictures in $\mathrm{CD}$ remains uncertain since collagen deposition occurs in the deeper layers of the intestinal wall, beyond the reach of biopsies [15].

A number of other techniques may help to identify the type of stenosis. First, with small bowel enteroclysis (fig. 2), the inflammatory stenosis shows a scarcely defined profile with wide irregular margins of the bowel wall (fig. 2A), while the fibrotic stricture is narrow and fixed, and the contrast medium easily visualized (fig. 2B). There is usually a classic pre-stenotic dilation (i.e. excessive widening of the lumen proximally to the narrowing; fig. $2 \mathrm{~B}$, arrow) in a fibrotic stricture, a feature often missing in the inflammatory stenosis (fig. 2A). Ultrasound, especially with contrast medium, may also be useful in differentiating between the two types of narrowing but it requires a great deal of expertise [40]. MRI using oral mannitol or polyethylene glycol for bowel opacification and intravenously infused gadoliniumDTPA as a contrast medium, has proven extremely valuable in determining the degree of inflammation in any given stenosis [41, 42]. Accumulation of gadolinium in the bowel wall indicates active inflammation with high accuracy (fig. 3A). On the contrary, its absence denotes fibrosis (fig. 3B). In addition to providing such information which may be essential for the management of the patient (see below) and which cannot be provided even by tissue biopsy, MRI is much safer than other procedures bearing virtually no radiation hazard. Indeed, MRI is slowly but surely replacing traditional small bowel enteroclysis as the elective morphologic study of the small intestine and should be recommended in the initial evaluation of intestinal strictures in $\mathrm{CD}$ [32]. At the present time, the cost and availability of the instruments remain limiting factors. Contrast-enhanced CT enterography also seems to hold great promise in assessing mu$\mathrm{ral}$ attenuation and thickness [43]. Finally, ${ }^{18} \mathrm{~F}$-fluorodeoxyglucose positron emission tomography, a method based on the rapid glucose turnover by inflamed tissue, also seems capable of distinguishing an inflammatory from a fibrotic stricture with good accuracy [44]. 
Fig. 3. Differential diagnosis between an inflammatory stenosis ( $\mathbf{A})$ and a fibrotic stricture (B): magnetic resonance imaging after intravenous gadolinium infusion. Note the accumulation of contrast medium in the bowel wall of the affected intestine in the presence of active inflammation (circle, $\mathbf{A}$ ) as opposed to the scarce uptake when the stricture is mostly fibrotic (circle, B).
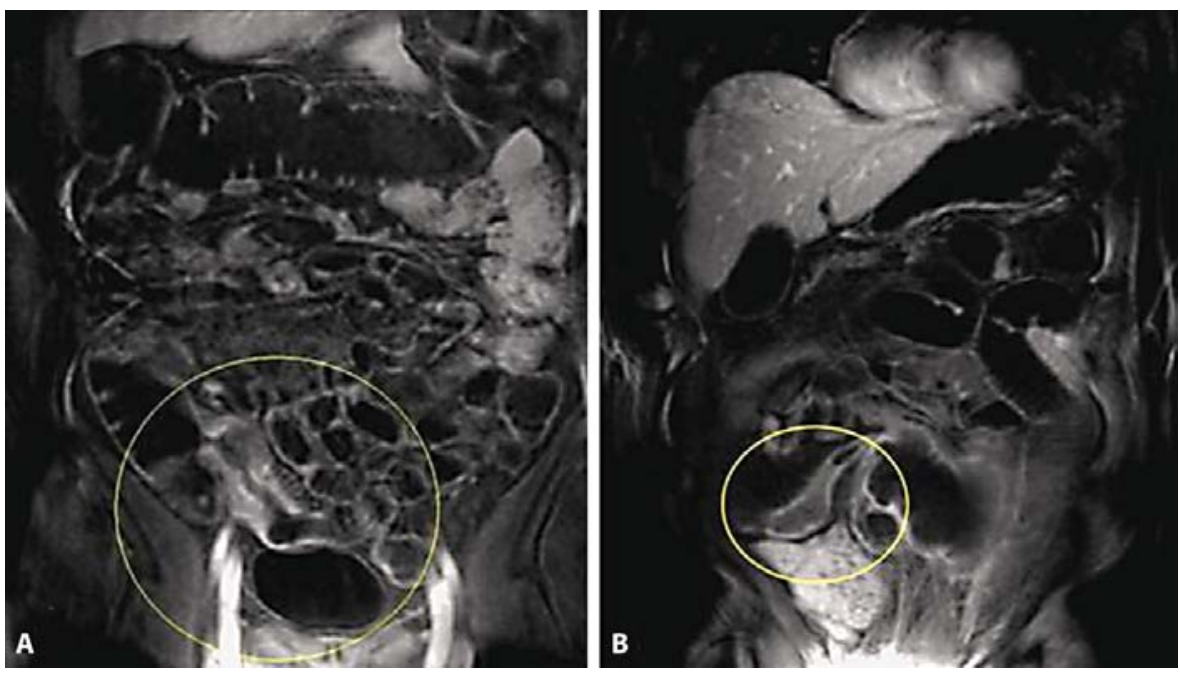

Fig. 4. Effect of infliximab on an inflammatory stenosis. The MRI picture after intravenous gadolinium infusion shows accumulation in the bowel wall before infliximab therapy indicating active inflammation (arrow, A) and its virtual disappearance after treatment (arrow, B) indicating that infliximab may actually be the treatment of choice in this situation. From Holtmann et al. [47], with permission from the author and Springer Science and Business Media.
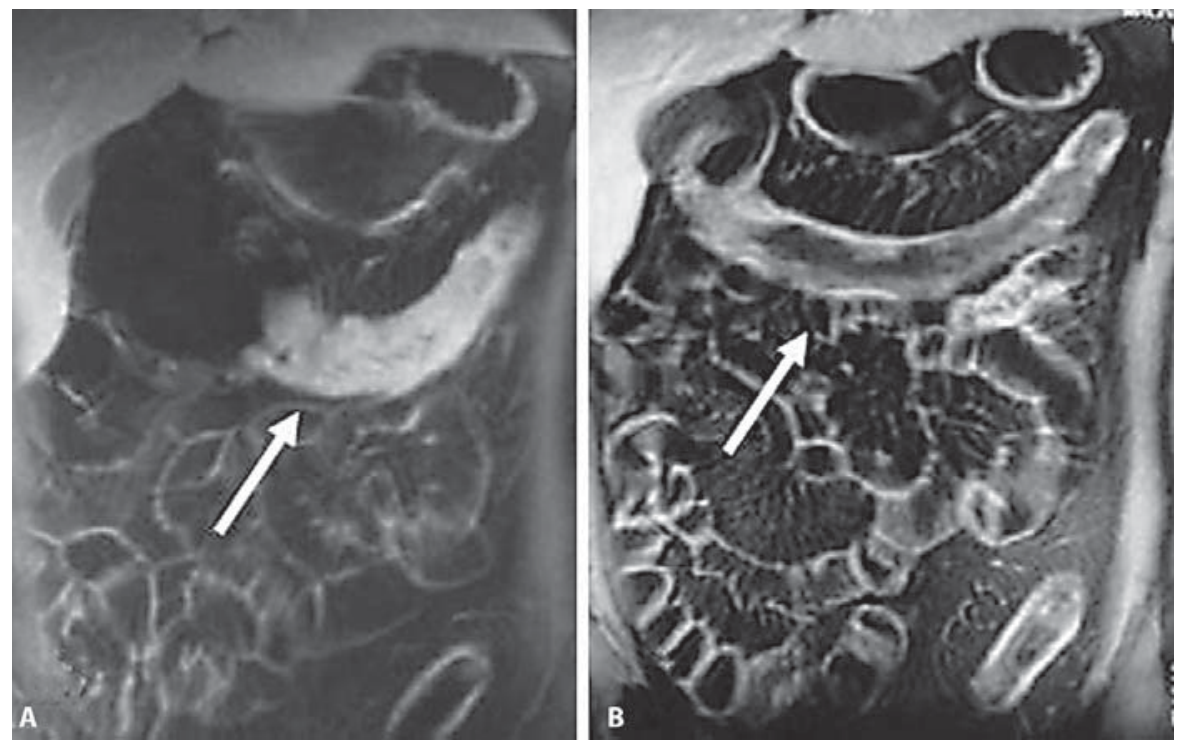

While MRI and CT enterography may greatly help to distinguish an inflammatory from a fibrotic stricture, there are few data in the literature regarding their potential incremental benefit in the management of strictures compared to the simple combination of radiographic findings and the clinical picture.

Indeed, in the presence of active inflammation the patient usually presents with several bowel movements per day, abdominal pain and general malaise. Leukocytosis can also be present while inflammatory indices (erythrocyte sedimentation rate and especially C-reactive protein) are frequently though not always elevated [45], and hemoglobin levels are often reduced. An elevation in fecal calprotectin appears to correlate with the degree of inflammation in CD [46] but its role, if any, in the differential diagnosis of intestinal strictures remains to be evaluated. On the contrary, the patient with an exclusively fibrotic stricture without active inflammation often has a quiescent, long-standing disease with only modest symptoms [14]. There may be overlapping clinical pictures when active inflammation in the stenosis is associated with the presence of fibrotic tissue (see below).

\section{Infliximab and Strictures in CD: Lessons from \\ Clinical Cases and Series}

To date the use of biologics in stricturing CD is limited to infliximab. Even with the latter, no randomized controlled trial has been conducted and only case or se- 
Fig. 5. Effect of infliximab on an inflammatory stenosis with a fibrotic component. The patient had a narrowing of the splenic flexure, with radiologic features consistent with a mostly inflammatory stenosis (A). Infliximab largely relieved the narrowing of the lumen except for a short, unresponsive tract (arrow, B), later proven to be of fibrotic nature by histological examination of the surgical piece. From Sorrentino et al. [48], with permission from the author and Springer Science and Business Media.
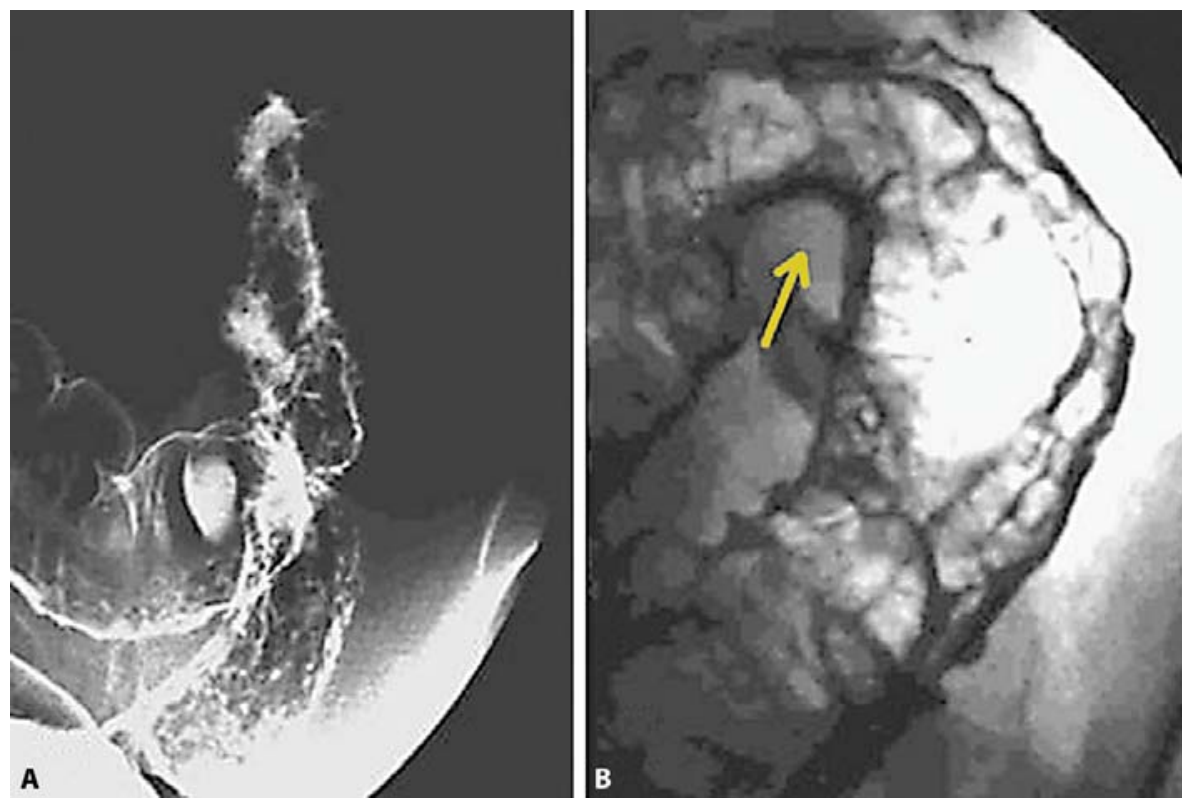

ries reports have been published so far [47-50]. Although initial, open pilot studies have been started [51, 52], additional data would certainly be desirable. However, at the present time, the design and conduct of such trials may be limited by inherent problems such as the capacity of individual centers to properly classify stenoses (i.e. fibrotic vs. inflammatory, length, location, lumen diameter) and, hence, to stratify patients. With this limitation in mind, published data can give us an insight into both the safety and efficacy of this medication in the presence of stenoses. These reports show that infliximab may be useful in the presence of active inflammation, whenever its powerful anti-inflammatory effect can improve transit by reducing cell infiltration and edema in the bowel wall. Since inflammation and fibrosis may coexist in the same stenosis different scenarios can be envisioned depending on the relative contribution of the two components (inflammatory and fibrotic) to the narrowing of the lumen.

When the stenosis is purely inflammatory (fig. 4A), the effect of infliximab is powerful, rapid and complete: the involved bowel wall thins out because cellular infiltration and edema disappear (fig. 4B) [47]. Improvement in the obstruction-like clinical picture in such cases is present and the effect is likely long-lasting. Thus, infliximab in this situation may well be the indication of choice [47].

Biologics and Other Therapies in Stricturing Crohn's Disease
When the stricture is mostly inflammatory (fig. 5A) but also presents a fibrotic component, infliximab largely relieves the narrowing of the lumen (fig. 5B). In the case illustrated in figure 5 a short tract (fig. 5B, arrow, later proven to be fibrotic by histological examination of the resected intestine) did not respond to the treatment [48]. However, symptomatic improvement (the patient had intermittent obstruction) was also significant in this case. Here, because of the presence of a fibrotic component, the effect of infliximab is less dramatic compared to the previous case but the indication to use it may still be present.

When a tight stricture with a pre-stenotic dilation is present (fig. 6A) many specialists choose to refer the patient to a surgeon. However, in this case the patient was symptomatic for active disease; MRI showed enrichment of gadolinium in the bowel wall (fig. 6B) and no signs or symptoms of obstruction were present. Here infliximab brought about an improvement in clinical symptoms and a clear increase in the lumen of the terminal ileum. However, the affected bowel walls remained scarcely distensible and the pre-stenotic dilation, although much reduced, was still present (fig. 6C) [49]. As in the previous cases, infliximab treatment brought about a dramatic resolution of the inflammatory component of the stricture which improved the patient's conditions. However, even after 1.5 years of therapy infliximab in no way affected the major fixed, fibrotic and likely irreversible

Digestion 2008;77:38-47 

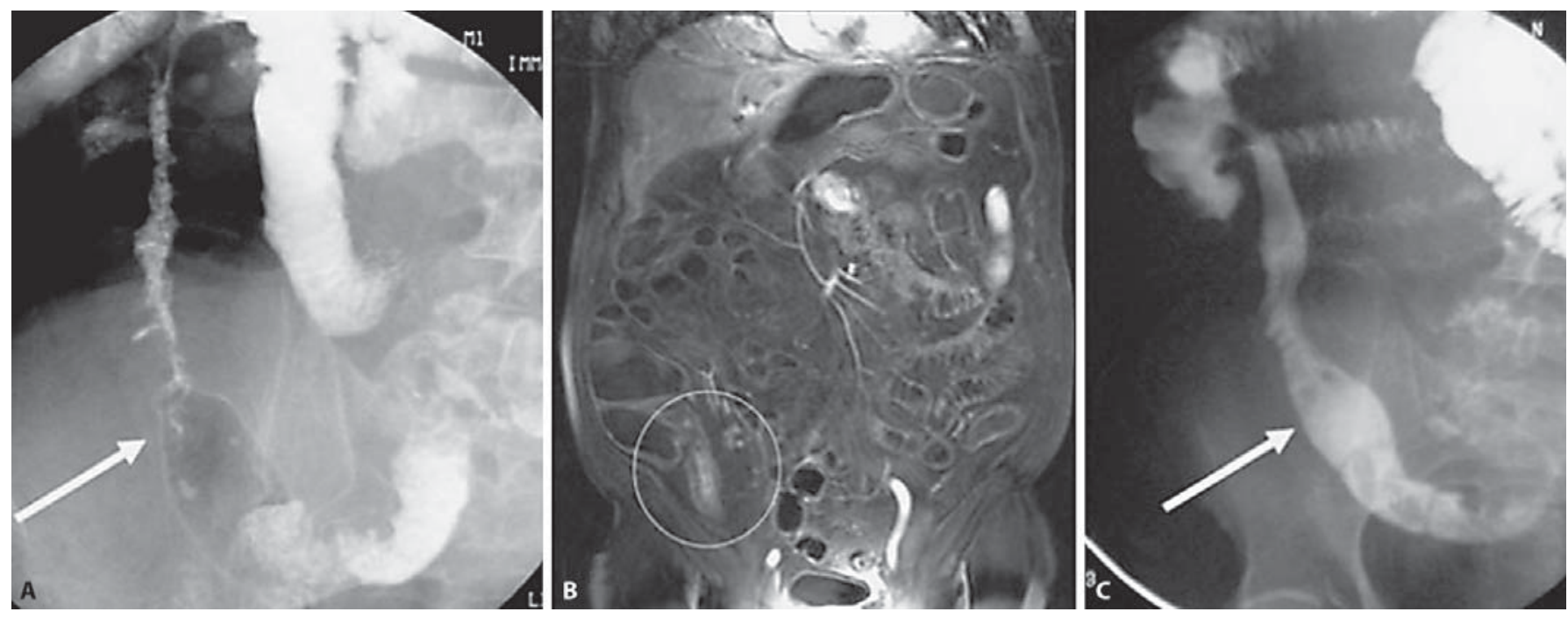

Fig. 6. Effect of infliximab on a fibrotic stricture with an inflammatory component. The patient had a tight, endoscopically impassable stricture in the terminal ileum (A) with a pre-stenotic dilation (arrow) suggesting that the stricture was essentially fibrotic. However, MRI after gadolinium uptake (B) showed the presence of an inflammatory component in the stricture (circle). In addition, the patient was symptomatic for active disease and

component of the stricture (fig. 6C) [49]. Here the indication to use medical therapy appears weaker and must be preceded by a thorough clinical evaluation: in the $a b$ sence of frank intestinal obstruction and of a septic focus, infliximab could be used, under careful observation, as a potential bridge to surgery. However, more data are needed to support the latter hypothesis.

Thus, although no systematic study has investigated the efficacy of infliximab in CD patients with an intestinal stenosis, it appears that the presence of a fibrotic component would be the major factor limiting efficacy. Indeed, on the basis of the cases described above, it appears, predictably, that the greater the degree of fibrosis in the stenosis the lesser the effect of the drug. To be effective infliximab should be given earlier in the course of disease, before collagen deposition has begun [53].

However, even when a fibrotic component is present and provided there is no contraindication such as clinical obstruction and/or a septic focus, this medication appears safe and could play a useful role: it does not cause new stenoses and does not worsen preexisting ones. had no signs or symptoms of obstruction. Infliximab brought about an improvement in clinical symptoms and a clear increase in the lumen of the affected bowel (C). However, the affected walls remained scarcely distensible and the pre-stenotic dilation, although much reduced, was still present (arrow) after 1.5 years of maintenance therapy. From Sorrentino et al. [49], with permission from the author and the publisher.

\section{Conclusions: A Working Model}

How can we use the information provided above in a practical clinical setting? Evidence-based guidelines cannot be proposed at the moment and must await additional randomized studies. However, available data as well as clinical experience and experts' opinion could be combined at the present time to design the algorithm presented in figure 7.

In a patient with $\mathrm{CD}$ and a suspected intestinal stricture, frank clinical obstruction should be immediately excluded. If the latter is present, the patient should be hospitalized and the obstruction managed as an urgent indication. Bowel rest, nasogastric suction and intravenous hydration remain the mainstays of supportive care. There is no consensus regarding the use of intravenous steroids in such a situation $[14,54,55]$. While anecdotal experience suggests that they may relieve acute obstruction caused by an inflammatory stenosis, solid evidence is still lacking. Indeed, some authorities prefer to adopt a 'wait and see' strategy (observation and supplementary measures only) since many acute obfor example, to fiber bolus impact in a narrowed intesstructions may spontaneously resolve in $24-48 \mathrm{~h}$ if due, 
Fig. 7. Approach to the clinical management of $C D$ patients with intestinal strictures. In any given patient with a suspected intestinal stricture, it is mandatory to exclude and immediately manage clinical obstruction and a septic focus. Further decisions may depend on the nature of the stricture itself, if present. Infliximab may be an excellent option when the narrowing is mostly inflammatory. For further details see text.

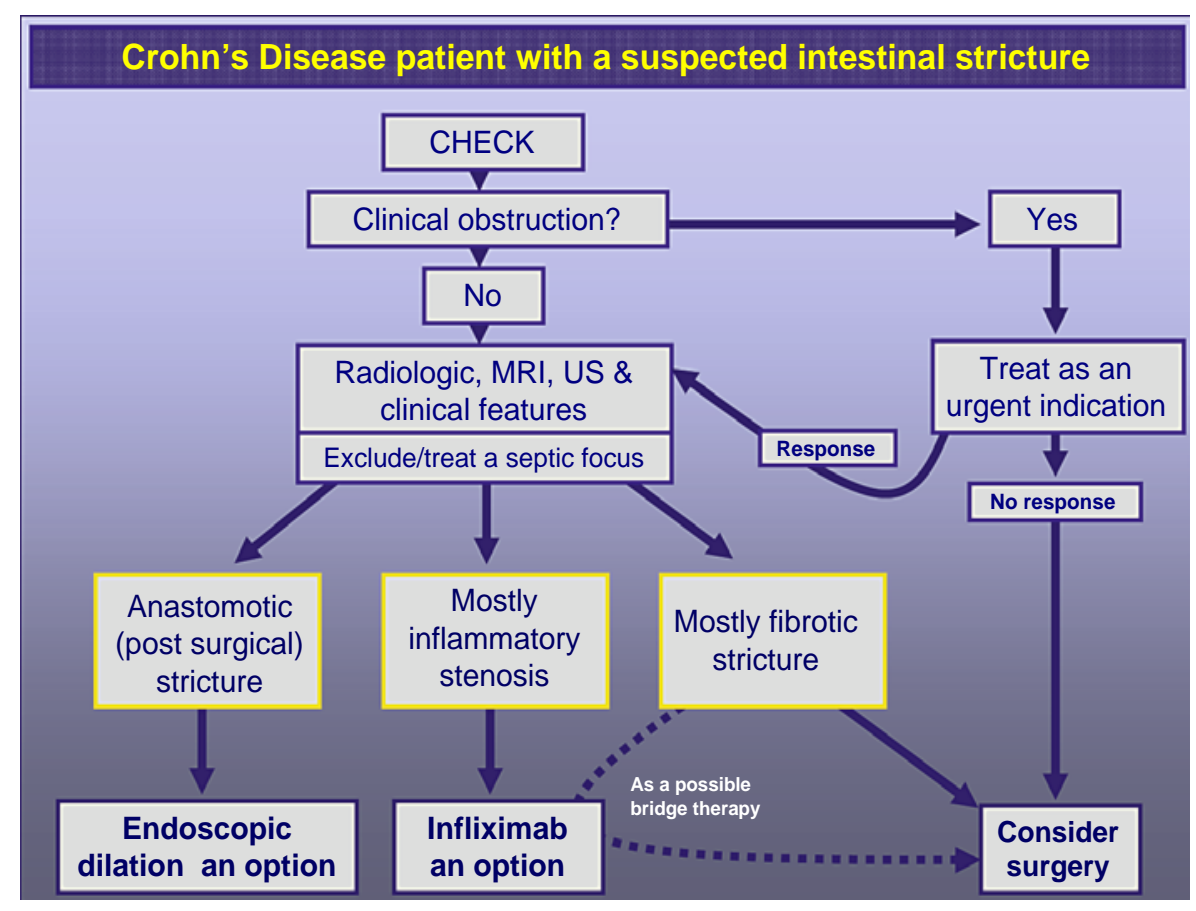

tinal segment [56]. Likewise, there is no evidence that immunosuppressive medications such as azathioprine/6-mercaptopurine may be effective in this situation [54]. This is not surprising given their slow onset of action. Biologics may act fast in relieving inflammation [47] and therefore be potentially very useful in resolving acute obstruction caused by an inflammatory stenosis. This is also suggested by a recent report describing the rapid resolution of acute Crohn's colitis by adalimumab [57]. However, at the present time the use of biologics in an urgent clinical setting remains an indication with limited evidence and can be recommended as such [58]. Future studies will clarify the role of infliximab and other biologics in this scenario and whether, in such situation, they may even be used as a diagnostic tool to distinguish between an inflammatory and a fibrotic stricture, based on their clinical efficacy in relieving obstructive symptoms.

It should be stressed that clinical obstruction in any given $\mathrm{CD}$ patient may be due not only to strictures or bolus impact but also to adhesions, a cause which will not respond to medical therapy and which is usually responsible of the most serious and sudden clinical symptoms [56]. It should also be kept in mind that an intestinal stenosis, both in the large and small intestine, may be due to e.g. cancer, radiation therapy, ischemia and previous di- verticulitis [59]. The latter causes, when appropriate, should be carefully excluded by endoscopy and biopsy for example, especially if a clear diagnosis of $\mathrm{CD}$ has not yet been made [59].

If medical management relieves obstruction, or clinical obstruction is absent from the outset, a more elective approach can be taken into consideration. As detailed above, radiologic, MRI, ultrasound and clinical features can be used to exclude/treat a septic focus (the next priority) and diagnose a stenosis as well as define its nature. The latter in turn will guide further therapeutic decisions. The management of anastomotic (post-surgical) strictures by endoscopic dilation in selected patients with a short fibrotic narrowing, favorable anatomy and in the absence of severe inflammation has been proven relatively effective and safe $[60,61]$ even though the procedure must often be repeated with time [62]. The use of this technique in the other CD-related strictures (see below) remains controversial $[63,64]$. In a purely inflammatory stenosis the evidence reviewed above suggests that infliximab may not only be effective but it may actually represent the indication of choice. In a mixed inflammatory/fibrotic stenosis infliximab can be used but it may only be partially effective. In a mostly fibrotic stricture infliximab may only be minimally effective and should be tried with caution since such patients with advanced, irreversible 
disease may actually independently develop clinical obstruction. Furthermore, a tight, fibrotic stricture can be associated with an internal fistula [65] a complication probably best managed by surgery [66]. As discussed above, more data are needed to support the hypothesis that in such a situation infliximab can be given as a bridge therapy before surgery.

While other therapies such as mesalamine, budesonide and immunosuppressives may also be indicated in active forms of CD [54], no data are available regarding their efficacy in specifically treating or preventing intestinal strictures in this disease, even aside from urgent indications. However, the therapeutic strategies proposed in figure 7 could in theory apply to an individual CD patient who is already under treatment with, e.g., azathioprine. Whether such medication should be continued if therapy with infliximab is initiated is unclear, especially in light of the serious adverse events recently attributed to the combination [67]. Here again, proper studies should address these important issues.

In conclusion, while proper clinical judgment should always decide whether it is time for surgery to play a role, current evidence appears to indicate that it is the nature of the stenoses (not stenoses per se) which should guide the clinical management and the choice of therapy in the individual CD patient.

\section{Conflict of Interest}

D. Sorrentino has acted as a consultant for Schering-Plough. This Study was not sponsored by the pharmaceutical industry.

\section{References}

1 Jewell DP, Satsangi J, Lobo A, et al: Infliximab use in Crohn's disease: impact on health care resources in the UK. Eur J Gastroenterol Hepatol 2005; 17:1047-1052.

$\checkmark 2$ van Dullemen HM, van Deventer SJ, Hommes DW, et al: Treatment of Crohn's disease with anti-tumor necrosis factor chimeric monoclonal antibody (cA2). Gastroenterology 1995;109:129-135.

>3 Targan SR, Hanauer SB, van Deventer SJ, et al: A short-term study of chimeric monoclonal antibody cA2 to tumor necrosis factor alpha for Crohn's disease. Crohn's disease cA2 study group. N Engl J Med 1997;337: 1029-1035.

4 Baert FJ, D’Haens GR, Peeters M, et al: Tumor necrosis factor alpha antibody (infliximab) therapy profoundly down-regulates the inflammation in Crohn's ileocolitis Gastroenterology 1999;116:22-28.

5 D'Haens G, Van Deventer S, Van Hogezand $\mathrm{R}$, et al: Endoscopic and histological healing with infliximab anti-tumor necrosis factor antibodies in Crohn's disease: A European multicenter trial. Gastroenterology 1999; 116:1029-1034.

6 Vasilopoulos S, Kugathasan S, Saeian K, et al: Intestinal strictures complicating initially successful infliximab treatment for luminal Crohn's disease. Am J Gastroenterol 2000; 95:2503.

7 Toy LS, Scherl EJ, Kornbluth A, et al: Complete bowel obstruction following initial response to infliximab therapy for Crohn's disease: a series of a newly described complication. Gastroenterology 2000;118:A2974.

8 REMICADE $^{\circledR}$ (infliximab) Prescribing Information. August 2004.
9 Hanauer SB: Crohn's disease: step up or top down therapy. Best Pract Res Clin Gastroenterol 2003;17:131-137.

10 Rieder F, Brenmoehl J, Leeb S, et al: Wound healing and fibrosis in intestinal disease. Gut 2007;56;130-139.

11 Di Sabatino A, Pender SLF, Jackson CL, et al: Functional modulation of Crohn's disease myofibroblasts by anti-TNF antibodies. Gastroenterology 2007;133:137-149.

12 Lichtenstein GR, Olson A, Travers S, et al: Factors associated with the development of intestinal strictures or obstructions in patients with Crohn's disease. Am J Gastroenterol 2006;101:1030-1038.

13 REMICADE $^{\circledR}$ (infliximab) Prescribing Information. September 2006.

14 Stenson WF: Inflammatory bowel disease; in Yamada T, Alpers DH, Laine L, Owyang C, Powell DW (eds): Yamada Textbook of Gastroenterology. Philadelphia, Lippincott Williams \& Wilkins, 1999, pp 1775-1839.

15 Geboes KP, Cabooter L, Geboes K: Contribution of morphology for the comprehension of mechanisms of fibrosis in inflammatory enterocolitis. Acta Gastroenterol Belg 2000;63:371-376.

16 Burke JP, Mulsow JJ, O’Keane C, et al: Fibrogenesis in Crohn's disease. Am J Gastroenterol 2007; 102:439-448.

17 Van Assche G, Geboes K, Rutgeerts P: Medical therapy for Crohn's disease strictures. Inflamm Bowel Dis 2004;10:55-60.

18 Pucilowska JB, Williams KL, Lund PK: Fibrosis in inflammatory bowel disease: cellular mediators and animal models. Am J Physiol 2000;279:G653-G659.
19 McKaig BC, Hughes K, Tighe PJ, et al: Differential expression of TGF isoforms by normal and inflammatory bowel disease intestinal myofibroblasts. Am J Physiol 2002;282. C172-C182.

20 Brannigan AE, Watson RW, Beddy D, et al: Increased adhesion molecule expression in serosal fibroblasts isolated from patients with inflammatory bowel disease is secondary to inflammation. Ann Surg 2002;235: 507-511.

21 Leask A, Holmes A, Black CM, et al: Connective tissue growth factor gene regulation. Requirements for its induction by transforming growth factor-beta 2 in fibroblasts. J Biol Chem 2003;278:13008-13015.

22 Bitzer M, von Gersdorff G, Liang D, et al: A mechanism of suppression of TGF beta/ SMAD signaling by NF-kappa B/RelA. Genes Dev 2000;14:187-197.

23 Di Sabatino A, Ciccocioppo R, Benazzato L, Sturniolo GC, Corazza GR: Infliximab downregulates basic fibroblast growth factor and vascular endothelial growth factor in Crohn's disease patients. Aliment Pharmacol Ther 2004;19:1019-1024.

24 Sands BE, Arsenault JE, Rosen MJ, et al: Risk of early surgery for Crohn's disease: implications for early treatment strategies. Am J Gastroenterol 2003;98:2712-2718.

25 Prantera C, Levenstein S, Capocaccia R, et al: Prediction of surgery for obstruction in Crohn's ileitis. A study of 64 patients. Dig Dis Sci 1987;32:1363-1369. 
-26 Silverberg MS, Satsangi J, Ahmad T, et al: Toward an integrated clinical, molecular and serological classification of inflammatory bowel disease: report of a Working Party of the 2005 Montreal World Congress of Gastroenterology. Can J Gastroenterol 2005; 19(suppl A):5-36.

-27 Louis E, Collard A, Oger AF, et al: Behaviour of Crohn's disease according to the Vienna classification: changing pattern over the course of the disease. Gut 2001;49:777-782.

-28 Cosnes J, Cattan S, Blain A, et al: Long-term evolution of disease behavior of Crohn's disease. Inflamm Bowel Dis 2002;8:244-250.

-29 Alvarez-Lobos M, Arostegui JI, Sans M, et al: Crohn's disease patients carrying NOD2/ CARD15 gene variants have an increased and early need for first surgery due to stricturing disease and higher rate of surgical recurrence. Ann Surg 2005;242:693-700.

30 Laghi L, Costa S, Saibeni S, et al: Carriage of CARD15 variants and smoking as risk factors for resective surgery in patients with Crohn's ileal disease. Aliment Pharmacol Ther 2005; 15;22:557-564.

- 31 Annese V, Lombardi G, Perri F, et al: Variants of CARD15 are associated with an aggressive clinical course of Crohn's disease an IG-IBD study. Am J Gastroenterol 2005; 100:84-92.

-32 Seiderer J, Brand S, Herrmann KA, et al: Predictive value of the CARD15 variant $1007 \mathrm{fs}$ for the diagnosis of intestinal stenoses and the need for surgery in Crohn's disease in clinical practice: results of a prospective study. Inflamm Bowel Dis 2006;12:11141121.

33 Louis E, Michel V, Hugot JP, et al: Early development of stricturing or penetrating pattern in Crohn's disease is influenced by disease location, number of flares, and smoking but not by NOD2/CARD15 genotype. Gut 2003;52:552-557.

34 Vermeire S: NOD2/CARD15: relevance in clinical practice. Best Pract Res Clin Gastroenterol 2004;18:569-575.

35 Waschke KA, Villani AC, Vermeire S, et al: Tumor necrosis factor receptor gene polymorphisms in Crohn's disease: association with clinical phenotypes. Am J Gastroenterol 2005;100:1126-1133.

-36 Warnaar N, Hofker HS, Maathuis MH, et al: Matrix metalloproteinases as profibrotic factors in terminal ileum in Crohn's disease. Inflamm Bowel Dis 2006;12:863-869.

37 Bataille F, Klebl F, Rummele P, et al: Histopathological parameters as predictors for the course of Crohn's disease. Virchows Arch 2003;443:501-507.

-38 Castiglione F, de Sio I, Cozzolino A, et al: Bowel wall thickness at abdominal ultrasound and the one-year-risk of surgery in patients with Crohn's disease. Am J Gastroenterol 2004;99:1977-1983.
39 Forcione DG, Rosen MJ, Kisiel JB, Sands BE: Anti-Saccharomyces cerevisiae antibody (ASCA) positivity is associated with increased risk for early surgery in Crohn's disease. Gut 2004;53:1117-1122.

40 Maconi G, Carsana L, Fociani P, et al: Small bowel stenosis in Crohn's disease: clinical, biochemical and ultrasonographic evaluation of histological features. Aliment Pharmacol Ther 2003;18:749-756.

41 Maccioni F, Bruni A, Viscido A, et al: MR imaging in patients with Crohn disease: value of T2- versus T1-weighted gadoliniumenhanced MR sequences with use of an oral superparamagnetic contrast agent. Radiology 2006;238:517-530.

42 Girometti R, Zuiani C, Toso F, Brondani G, Sorrentino D, Avellini C, Bazzocchi M: MRI scoring system including dynamic motility evaluation in assessing the activity of Crohn's disease of the terminal ileum. Acad Radiol 2008;15:153-164.

43 Bodily KD, Fletcher JG, Solem CA, et al: Crohn disease: mural attenuation and thickness at contrast-enhanced CT enterography - correlation with endoscopic and histologic findings of inflammation. Radiology 2006;238:505-516.

44 Neurath MF, Vehling D, Schunk K, et al: Noninvasive assessment of Crohn's disease activity: a comparison of 18F-fluorodeoxyglucose positron emission tomography, hydromagnetic resonance imaging, and granulocyte scintigraphy with labeled antibodies. Am J Gastroenterol 2002;97:1978-1985.

45 Solem CA, Loftus EV Jr, Tremaine WJ, Harmsen WS, Zinsmeister AR, Sandborn WJ: Correlation of C-reactive protein with clinical, endoscopic, histologic, and radiographic activity in inflammatory bowel disease. Inflamm Bowel Dis 2005;11:707-712.

46 Vermeire S, Van Assche G, Rutgeerts P: Laboratory markers in IBD: useful, magic, or unnecessary toys? Gut 2006;55:426-431.

47 Holtmann MH, Neurath MF: Anti-TNF strategies in stenosing and fistulizing Crohn's disease. Int J Colorectal Dis 2005;20:1-8.

48 Sorrentino D, Avellini C, Beltrami CA, et al: Selective effect of infliximab on the inflammatory component of a colonic stricture in Crohn's disease. Int J Colorectal Dis 2006;21: 276-281.

49 Sorrentino D, Terrosu G, Vadalà S, Avellini C: Fibrotic strictures and anti TNF- $\alpha$ therapy in Crohn's disease. Digestion 2007;75:22-24.

50 Knapp AB, Mirsky FJ, Dillon EH, Korelitz BI: Successful infliximab therapy for a duodenal stricture caused by Crohn's disease. Inflamm Bowel Dis 2005;11:1123-1125.

51 Pallotta N, Barberani F, Hassan NA, et al: Effect of infliximab on small bowel stenoses in Crohn's disease (abstract). Gastroenterology 2007;132:S1137.

52 Louis E, Boverie J, Dewit O, et al: Treatment of small bowel subocclusive Crohn's disease with infliximab: an open pilot study. Acta Gastroenterol Belg 2007;70:15-19.
3 Sorrentino D, Terrosu G, Avellini C, Maiero S: Infliximab with low dose methotrexate for prevention of post surgical recurrence of ileocolonic Crohn's disease. Arch Intern Med 2007;167:1804-1807.

54 Lichtenstein GR, Abreu MT, Cohen R, Tremaine W: American Gastroenterological Association Institute technical review on corticosteroids, immunomodulators, and infliximab in inflammatory bowel disease. Gastroenterology 2006;130:940-987.

55 Su C, Lichtenstein GR: Crohn's disease of the small bowel; in Bayless TM, Diehl AM (eds): Advanced Therapy in Gastroenterology and Liver Disease. Hamilton, Decker, 2005, pp 275-279.

56 Sachar DB: Ten common errors in the management of inflammatory bowel disease. Inflamm Bowel Dis 2003;9:205-209.

57 Ng SC, Kamm MA: Fulminant Crohn's colitis: when only an antibody will do. Inflamm Bowel Dis 2007;13:971-974.

58 Clark M, Colombel JF, Feagan BC, et al: American Gastroenterological Association consensus development conference on the use of biologics in the treatment of inflammatory bowel disease, June 21-23, 2006. Gastroenterology 2007;133:312-339.

59 Kozarek R: Stenoses of small bowel and colon; in Bayless TM, Diehl AM (eds): Advanced Therapy in Gastroenterology and Liver Disease. Hamilton, Decker, 2005, pp 351-357.

60 Ferlitsch A, Reinisch W, Püspök A, et al: Safety and efficacy of endoscopic balloon dilation for treatment of Crohn's disease strictures. Endoscopy 2006;38:483-487.

61 Pohl J, May A, Nachbar L, Ell C: Diagnostic and therapeutic yield of push-and-pull enteroscopy for symptomatic small bowel Crohn's disease strictures. Eur J Gastroenterol Hepatol 2007;19:529-534.

62 Morini S, Hassan C, Lorenzetti R, et al: Long-term outcome of endoscopic pneumatic dilatation in Crohn's disease. Dig Liver Dis 2003;35:893-897.

63 Van Assche G, Vermeire S, Rutgeerts P: Endoscopic therapy of strictures in Crohn's disease. Inflamm Bowel Dis 2007;13:359-361.

64 Koltun WA: Dangers associated with endoscopic management of strictures in IBD. Inflamm Bowel Dis 2007;13:356-358.

65 Oberhuber G, Stangl PC, Vogelsang H, et al: Significant association of strictures and internal fistula formation in Crohn's disease. Virchows Arch 2000;437:293-297.

66 Miehsler W, Reinisch W, Kazemi-Shirazi L, et al: Infliximab: lack of efficacy on perforating complications in Crohn's disease. Inflamm Bowel Dis 2004;10:36-40.

67 Sorrentino D, Terrosu G, Avellini C: Risks of combining immunosuppressives and biological treatments in inflammatory bowel disease. Arch Intern Med 2008, in press. 